\title{
Impact of Sacubitril and RAAS inhibitors on p53 expression in rat-induced heart failure. A new approach for ischemic heart disease therapy
}

\author{
Kawa Dizaye*, Rojgar H. Ali**, Rafal Al-Rawi ${ }^{\star \star \star}$ \\ ${ }^{*}$ College of Medicine, Hawler Medical University, Erbil, Iraq, ${ }^{*}$ College of Pharmacy, Hawler Medical University, \\ Erbil, Iraq, ${ }^{* \star *}$ Department of Clinical Analysis, College of Pharmacy, Hawler Medical University, Erbil, Iraq. \\ Correspondence: kawa.dizaye@hmu.edu.iq
}

(Ann Coll Med Mosul 2020; 42 (1):11-18).

Received: $26^{\text {th }}$ Jan. 2020; Accepted: $8^{\text {th }}$ June 2020.

\begin{abstract}
Background: p53 is a well-known protein that prevents cancer formation, which is recognized as the main protein in the adaptation to many harmful stimuli, like oxidative stress. Among actions of p53, studies have shown that it has an important role in the development of heart failure (HF), and arteriosclerosis. Several clinical studies were done to investigate the role of p53 in the progression of HF and with the intention to improve management of heart failure.

Objective: The purpose of this work was to investigate the mechanisms of myocardial injury that precipitates heart failure that is mediated by both $\beta$-adrenergic signaling and p53, then compare the results with administered sacubitril and angiotensin system blockers.

Methods: Thirty female albino rats (aged around 8 months weighing $230 \mathrm{~g}$ ) in average were allocated into five groups; group I: served as a control group; group II: were injected with isoproterenol for HF induction; and groups III, IV, and V (HF treated groups ) whereas rats received sacubitril alone, combination of sacubitril with ramipril and combination of sacubitril with aliskiren respectively, orally on daily basis.

Results: Results revealed that rats of group II (HF induced) were significantly $(P=0.002)$ showed more myocardial injury and higher nuclear p53 expression compared to rats of the control group. Furthermore, rats of group III, IV, V (HF treated groups) showed significantly $(P=0.037)$ less myocardial injury and significantly $(P=0.015)$ less nuclear p53 expression compared to rats of the group II.

Conclusions: It was concluded that rats received either sacubitril alone or with combination of ramipril or aliskiren for HF treatment were alleviated myocardial injury and lower nuclear p53 expression.

It was concluded that anti-p53 approach may provide a novel therapeutic strategy for human ischemic heart diseases and myocardial infarction.
\end{abstract}

Keywords: p53, Isoprenaline, Sacubitril, Heart failure.

$$
\begin{aligned}
& \text { تاثير ساكيوباتريل و ماتعات الراس علي P53 في الفئران المحرضه لقصور }
\end{aligned}
$$

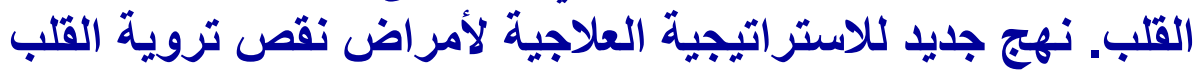

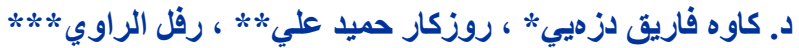

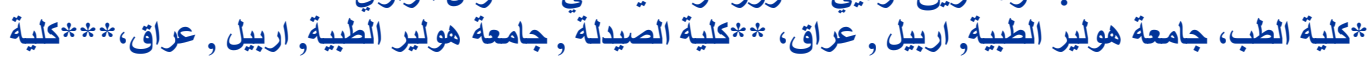

$$
\begin{aligned}
& \text { الصيدلة , جامعة هولير الطبية, اربيل , عراق. }
\end{aligned}
$$

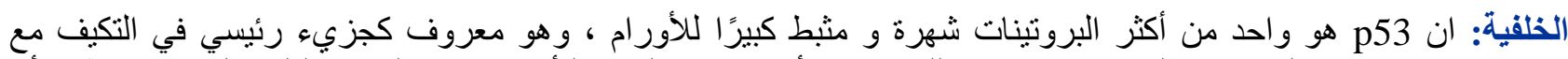

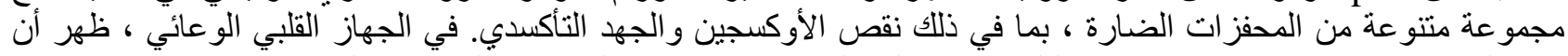

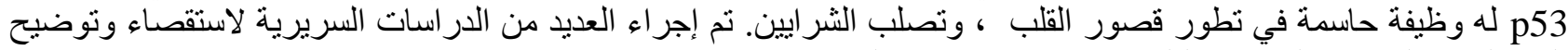

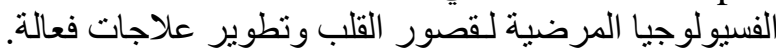
الهاف: الهدف من هذه الدراسة هو التحقيق و التحري في آليات إصابة عضلة القلب التي تؤدي إلى قصور القلب التي يسببها كل من الإشارات الأدرينالية p-adrenergic و p53 ، ثم مقارنة النتائج مع استعمال الادويه العلاجيه Sacubitril و .ramipril 
طرق العمل: في هذه الدراسة ، تم تخصيص 30 أنثى من فئران الوستر البيضاء في خمس مجموعات ؛ المجموعة الأولى:

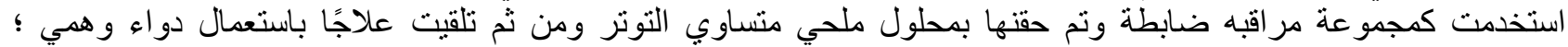

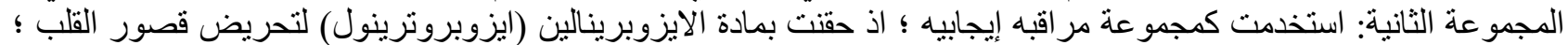

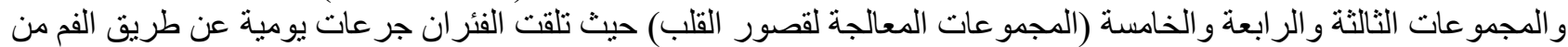
sacubitril

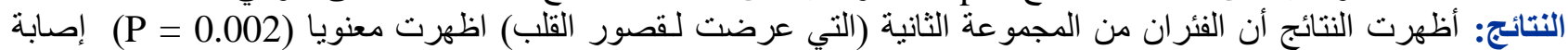

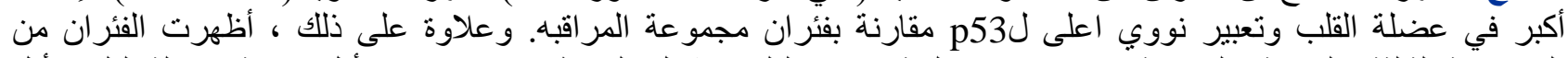

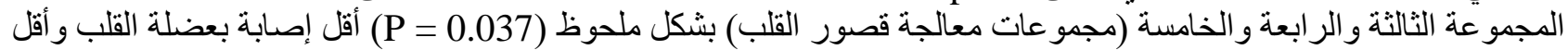
(P = 0.015) تعبير للبروتين p53 النووي مقارنة مع الفئر ان من المجمو عة الثنانيه.

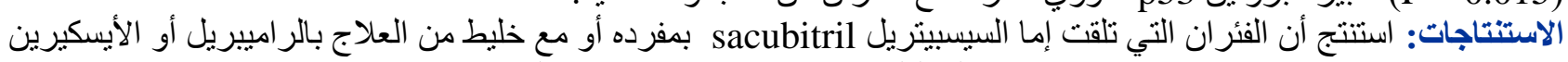
ramipril or aliskiren

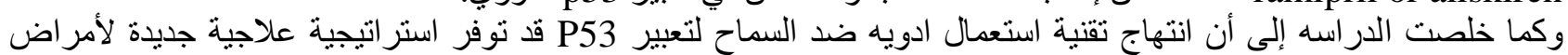
نقص تروية القلب البشرية و احتشاءعضلة القلب.

الكلمات المفتاحية: الفئران, قصور القلب, P53, ساكيوباتريل, ايسوبرينالين.

\section{INTRODUCTION}

I he main function of the heart is to provide enough force to pump blood to various parts of our body so as oxygen and nutrients are provided. A defect in the function of the heart may cause critical negative consequences to the human body. Recent studies recognized p53, which is suppressing tumor formation, to have an important role in the progression of heart failure. The main function of p53 is that it induces a group of molecules that cause programmed cell death, arrest cell growth, and inhibit angiogenesis ${ }^{1}$. Heart failure (HF) is a major cause of morbidity and mortality worldwide ${ }^{2}$. p53 is a gene that plays a big role in the expression of many other genes. Recognizing the genes that play major roles in maintaining cardiac tissue homeostasis is considered of great importance ${ }^{3}$. Normally, the expression of p53 is maintained by cells at its minimum levels by a certain protein which is called mouse double minute 2 homolog (MDM2). During an acute stress, mouse double minute 2 homolog is inactivated and the enhanced p53 expression will inhibit cell division and induce programmed cell death ${ }^{4}$. Myocyte programmed cell death is a wellknown pathological phenomenon that happens in several types of cardiac diseases ${ }^{5}$. p53 induces apoptosis and cell growth retardation through stress pathway ${ }^{6}$. Apoptosis is a process that control programmed cell death following a particular cellular challenge 7 . Isoprenaline, or isoproterenol, is a drug used for the management of heart block. It's a catecholamine that non selectively activates $\beta$-adrenoreceptor ${ }^{8}$. Sacubitril, after metabolism, blocks a neutral endopeptidase (neprilysin) which is responsible for terminating the action of natriuretic peptides ${ }^{9}$
Aliskirin is acting through inhibiting of active sites of renin enzyme thereby reducing the activation of renin angiotensin aldosterone system which plays an important role in deteriorating heart failure condition, whereas ramipril is acting through inhibiting the enzyme responsible for converting angiotensin I into angiotensin II ${ }^{10}$.

\section{METHODS}

\section{Animals}

Thirty female albino rats (5 to 6 months old, weighing 240-285 g) were used in this study. Rats were kept in rat cages in the animal facility at Hawler Medical University, rats were having free access to food and water. The animal room was programmed on half-day of light-dark cycles at $20 \pm$ $5^{\circ} \mathrm{C}$ and $20-30 \%$ humidity.

\section{Ethics Statement:}

The ethics committee at the university has approved ethics measures for this work numbered 180502171.

\section{Experimental protocol: \\ Study design}

The rats were allocated into five groups with Completely Randomized Design (CRD) with 6 rats each $(n=6)$ :

1-Group I: control group.

2-Group II: positive control group; heart failure was induced in this group of rats with intraperitoneal isoproterenol $5 \mathrm{mg} / \mathrm{kg}$ for seven days. Rats were then administered placebo for 14 days ${ }^{11}$.

Heart failure was induced in groups III, IV, and V rats using same mentioned method that has been used for rats in group II. Then:

3-Group III: treated with sacubitril $30 \mathrm{mg} / \mathrm{kg} / \mathrm{day}$ for two weeks ${ }^{12}$. 
4-Group IV: treated with sacubitril $30 \mathrm{mg} / \mathrm{kg} /$ dayramipril $10 \mathrm{mg} / \mathrm{kg} /$ day orally for 2 weeks ${ }^{13}$.

5-Group V: treated with sacubitril $30 \mathrm{mg} / \mathrm{kg} /$ dayaliskiren $10 \mathrm{mg} / \mathrm{kg} /$ day orally for 2 weeks ${ }^{14}$.

Histopathological evaluations: myocardial tissue was fixed in $10 \%$ formalin. Blocks of the specimens were prepared using paraffin and then fine slices were made using microtome $(6 \mu \mathrm{m})$ and placed on cleaned glass slides, then sections were stained with hematoxylin and eosin. The slides were examined using light microscope under different powers in histopathology laboratory at college of pharmacy, Hawler Medical University.

Semiquantitative scoring systems for myocardial injury

The severity and level of myocardial injury were observed for each case. The observations were divided into the below grades, in order to compose a range of histologic myocardial injury: (0) No change: (1) Mild - focal myocyte damage or small multifocal degeneration with slight degree of inflammation and fibrosis (2) Moderate myofibrillar degeneration with moderate inflammatory process and fibrosis, (3) Severe myocardial injury with diffuse inflammatory and fibrosis process ${ }^{15,16}$.

p53 immunoscore measurement:

The fraction of p53 positive nuclei as p53 immunohistochemical scoring system was implemented. The fraction of p53 immunoreactive cells was scored as 0 to $3+$ in p53 positive regions. Nuclear p53 expression in $\geq 10 \%$ of the cells was scored as over expression, and were scored according to the 3-tiered system as following < $10 \%-, 10 \%-30 \%+, 31 \%-50 \%++$, and $>50 \%+++$ 17 .

Mouse Monoclonal anti-p53, Clone BP-53-12 pre dilute Antibody, Ready-To-Use, the method according to Dako recommendation was used to stain tissue by Anti- p53 antibody.

\section{Statistical Analysis}

Statistical Analysis was done by using GraphPad Software statistical package computer software. Contingency tables have been formed and built up to figure out the association between biomedical variable investigated. Fisher's exact test was used to calculate the significant differences between studied variables. A probability value of less than 0.05 was considered statistically significant ${ }^{18}$.

\section{RESULTS}

Results revealed that rats of group II (HF induce group) significantly $(P=0.002)$ showed more myocardial injury compared to rats of the control group I. Two 2 rats in group 2 showed moderate myocardial injuries as well as 4 rats showed severe myocardial injury with diffuse inflammatory process. Furthermore, rats of group III, group IV, and group $\mathrm{V}$, (HF treated groups) showed significantly $(P=0.037)$ less myocardial injury compared to the rats of the group II. Three rats of groups III, IV, and V showed mild myocardial injury, mild degree of inflammation and mild fibrosis and 3 rats showed moderate myocardial injury with moderate inflammatory process and moderate fibrosis (Figure1). These results indicate that injection rats with isoprenaline (isoproterenol) then received either sacubitril alone or with a combination of ramipril or aliskiren alleviated myocardial injury (Table 1).

Table 1. Myocardial injury scoring and extent of Severity of myocardial injury

\begin{tabular}{|l|l|l|l|l|l|}
\hline $\begin{array}{l}\text { Myocardial } \\
\text { injury } \\
\text { scoring }\end{array}$ & $\begin{array}{l}\text { No } \\
\text { change }\end{array}$ & $\begin{array}{l}\text { Mild } \\
(1)\end{array}$ & $\begin{array}{l}\text { Moderate } \\
(2)\end{array}$ & $\begin{array}{l}\text { Severe } \\
(3)\end{array}$ & $\begin{array}{l}P \\
\text { value }\end{array}$ \\
\hline $\begin{array}{l}\text { Control } \\
\text { group (I) }\end{array}$ & 6 & 0 & 0 & 0 & \multirow{2}{*}{0.002} \\
\hline Group (II) & 0 & 0 & 2 & 4 & \multirow{2}{*}{0.037} \\
$\begin{array}{l}\text { *Groups III, } \\
\text { IV, and V }\end{array}$ & 0 & 3 & 3 & 0 & \\
\hline
\end{tabular}

Immunohistochemical expression of p53 is presented in Table 2. Rats of group II (HF induce group) significantly $(P=0.002)$ showed higher nuclear p53 expression compared to the rats of the control group I. All 6 rats in group II showed (10\%-30\%) nuclear p53 expression compared to < $10 \%$, for rats of control group. Moreover, rats of group III, group IV, and group V, (HF treated groups) showed significantly $(P=0.015)$ less nuclear p53 expression compared to the rats of the group II. Five rats showed $<10 \%$ and just one rat showed 10\%-30\% nuclear p53 expression, compared to 6 rats of group II with 10\%-30\% (Figure2). These results indicate that injection rats with isoprenaline (isoproterenol) then administered either sacubitril alone or with combination of ramipril or combination of aliskiren reduce nuclear p53 expression (Table 2). 
Table 2. Immunohistochemical expression of p53.

\begin{tabular}{|l|l|l|l|l|l|}
\hline $\begin{array}{l}\text { Nuclear pespression } \\
\text { exp }\end{array}$ & $\begin{array}{l}+ \\
(<10 \%)\end{array}$ & $\begin{array}{l}++ \\
(10 \%-30 \%)\end{array}$ & $\begin{array}{l}+++ \\
(31 \%-50 \%)\end{array}$ & $P$ value \\
\hline Control group (I) & 6 & 0 & 0 & 0 & 0.002 \\
\hline Group (II) & 0 & 6 & 0 & 0 & 0.015 \\
\hline *Groups III, IV, and V & 5 & 1 & 0 & 0 & \\
\hline
\end{tabular}

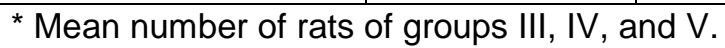
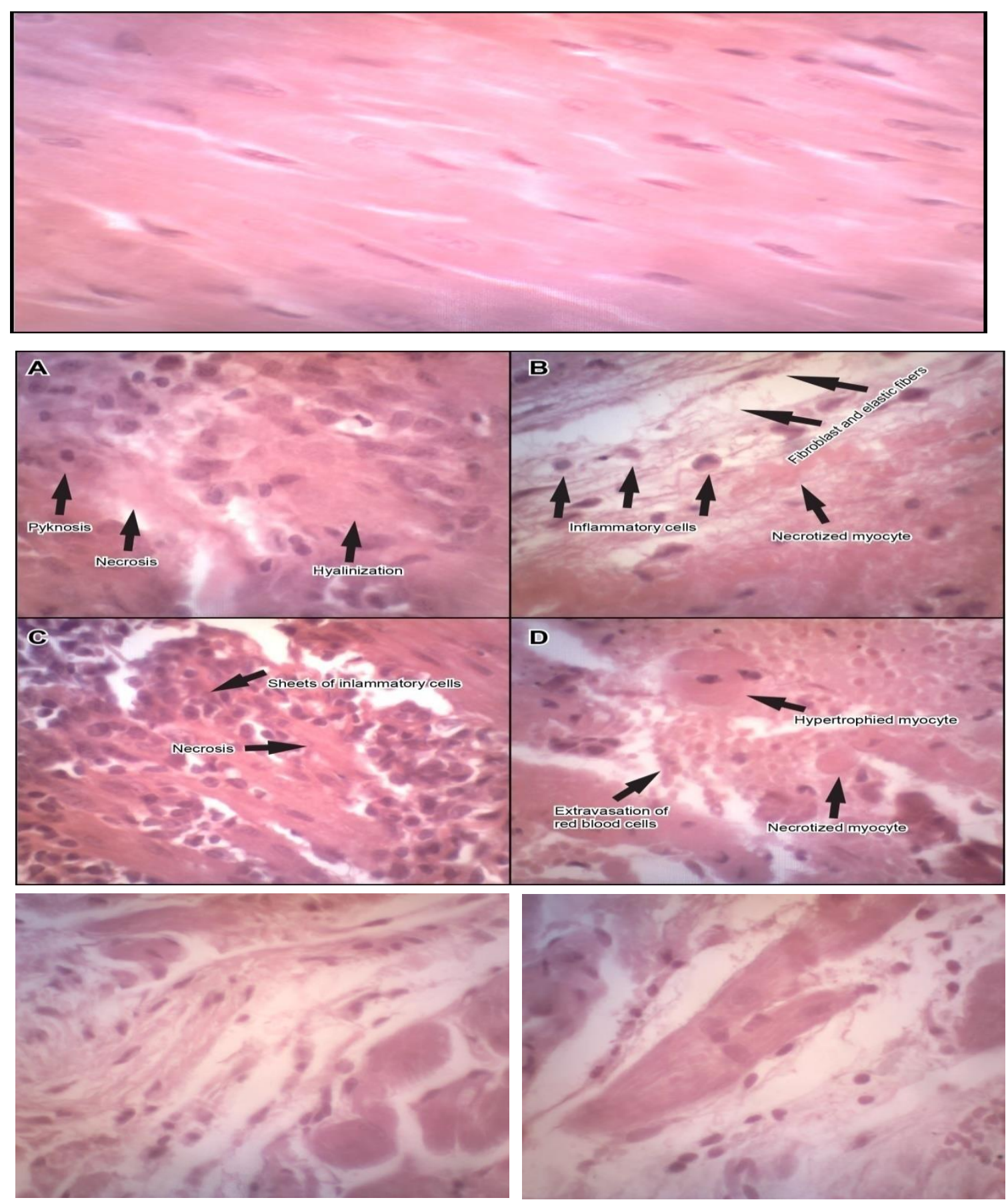
Figure1: Histological examination of myocardial tissue, hematoxylin and eosin stain. (A) group I (control group)showed normal architecture (B,1,2,3,4) group II (HF induce group) showed myocardial cells death and degeneration ,hyalinization of muscle fibers, inflammatory cells infiltration and fibrosis (C) group III, group IV, and group V, (HF treated groups) showed reduced myocardial damage, less inflammatory cells infiltration and remodeling of the fibrotic change with cardioprotective effect (400x)
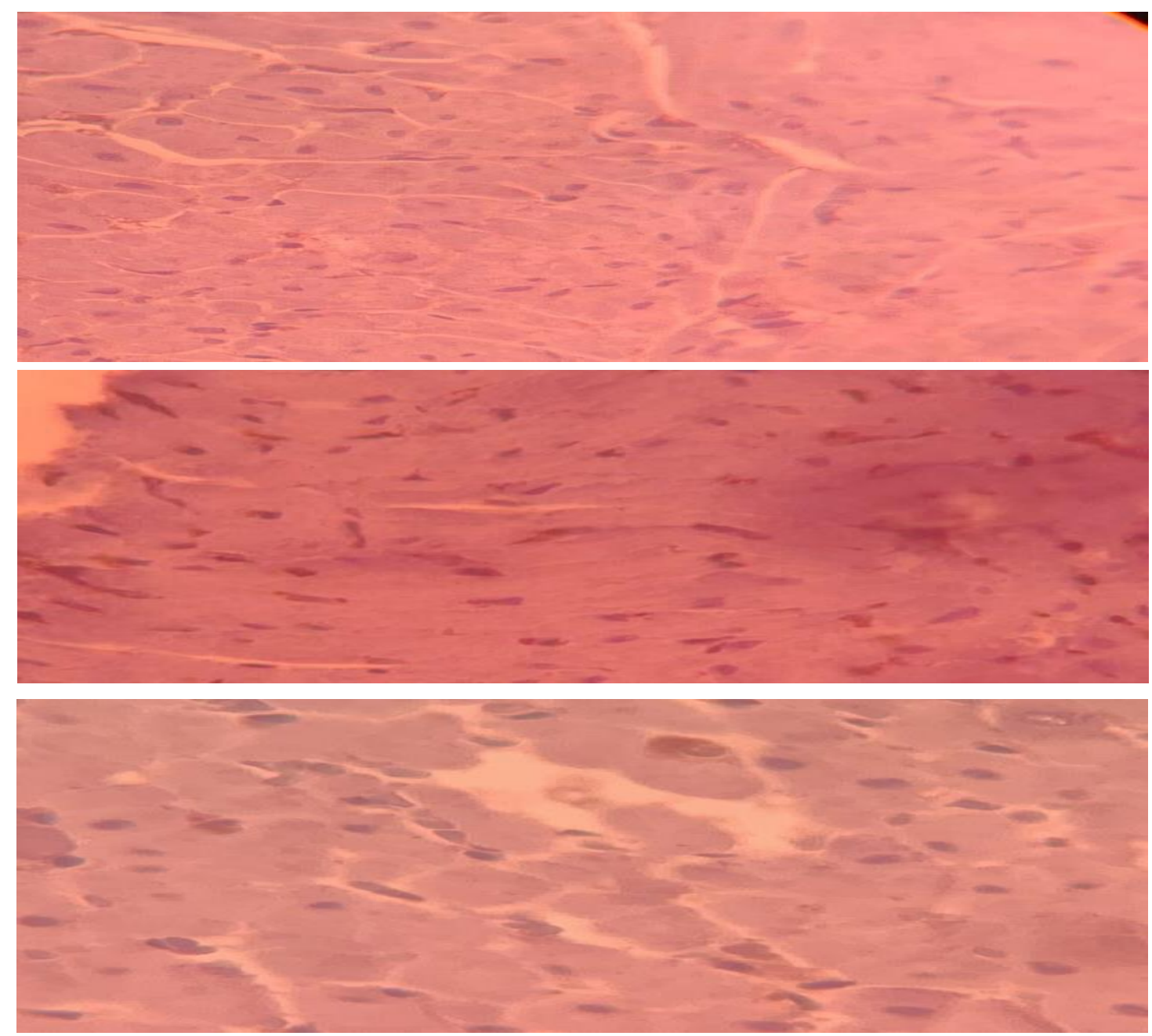

Figure2: Expression of P53determined by immunoreactivity in representative sections of myocardial tissue. (A) group I (control group)showed nuclear p53 expression scored $<10 \%(-)$ (B) group II (HF induce group) showed nuclear p53 expression (10\%-30\%) (+) (C) group III, group IV, and group V, (HF treated groups) showed nuclear p53 expression scored $<10 \%(-)(400 \mathrm{x})$.

\section{DISCUSSION}

Recognizing the factors that regulate and preserve cardiac tissue function is of clinical and scientific importance. It was reported that induction of cardiomyopathy by isoprenaline intraperitoneally revealed Cardiomyocyte injury, inflammatory response with a predominance of macrophages within rat myocardial tissue ${ }^{19,20}$, which is similar to our result which showed that isoproterenol caused moderate to severe myocardial injuries and inflammatory changes and also agreed with Heraldo et al results ${ }^{15}$. Other report also found that isoproterenol induced myocardial ischemia, cardiotoxicity and cardiac fibrosis ${ }^{21}$.

The result of this study found that rats of group II (HF induce group), where rats injected with isoproterenol showed cardiac hypertrophy, which is in agreement with others who found that Neuroglobin affects cardiac hypertrophy though including p53-mediated apoptosis ${ }^{7}$. Furthermore, interstitial fluid was also observed in rats of group II while less interstitial fluid was notice in HF treated groups. 
This result was similar to that reported earlier ${ }^{22}$. Also, it was noticed in this investigation that interstitial fibrosis with collagen fibers were more prominent in group II, in contrast to myocytes from HF treated groups (Group III, IV, and V), where rats had myofibrils interspersed with few collagen bundles indicating remodeling effect, which confirms other report ${ }^{23}$. On the other hand, study indicated that sacubitril combined with other medications improved the imbalance between the renin and natriuretic peptide systems, which may due to the inhibition of inflammation response of macrophages which might have a cardioprotective effect 24 . It was reported that sacubitril and valsartan protected myocardial infarction through inhibiting neprilysin in isoproterenol- induced myocardial infarction ameliorating oxidative damage in rats ${ }^{25}$.

Result of this study revealed that p53 protein was minimally stained in control group of less than $10 \%$ of the cardiomyocytes. In contrast, p53 positive stained nuclear was significantly increased in group II cardiomyocytes (HF induced group) of rats with severe inflammatory changes, while p53 expression reduced to less than $10 \%$ in HF treated groups III, IV, and V. Similar finding was found ${ }^{26}$. Moreover, p53 was shown to be upregulated when coexists with isoproterenol in rat cultured myocardial tissue 27 . Protein level of p53 is also kept low in myocardial tissue but it increased when cardiac cells exposed to hypoxia ${ }^{28}$. p53 blocks cell growth during stress by modifying gene transcription. Another vital question that could be raised is how the level of p53 activity could play a role in the protection against external stressing events in addition to provide a possible novel therapeutic technique ${ }^{3}$. Increased p53 expression is related with myocardial tissue programmed cell death in advanced heart failure ${ }^{25}$. Other study suggested that deletion or inhibition of p53 activity can prevent or reduce the occurrence of heart failure 29

So it means that there is an association between p53 upregulation and human $\mathrm{HF}^{30}$. Su et al findings revealed a novel regulatory mechanism of ROCK1/p53/NOXA signaling in modulating myocardial apoptosis in vitro and with congenital cardiac defects in vivo ${ }^{31}$. Recently, the roadblocks in charge of adult myocyte cell cycle cessation located at the center of developing regenerative therapies for cardiovascular diseases. Therefore, it is suggested that blockade of p53/Mdm2-regulated mitochondrial RNAs would promote the expression of cell cycle activators leading to proliferation of adult murine cardiomyocytes ${ }^{32}$. It was stated that the cell deaths of differentiated cells, directly influence tissue function. This may lead to a clue for a novel therapy working through counter acting apoptosis processes $^{33}$. Apoptosis constitutes an important event in the pathogenesis of $\mathrm{HF}^{34}$. Similarly, it has been suggested that anti-p53 strategy would be effective in preventing ischemic injury and in myocardial infarction treatment ${ }^{35}$. Enhancing the effect of anti-p53 mediates a beneficial effect on myocardial function. and inhibiting cell death in failing myocardium is considered as an approach to prevent and manage $\mathrm{HF}^{36}$.

\section{CONCLUSIONS}

This study confirmed the suggestion that p53 acts as a regulator protein for cardiac function and structure. It was concluded that anti-p53 approach may provide a novel therapeutic strategy for human ischemic heart diseases and myocardial infarction.

\section{REFERENCES}

1. Takayuki F, Yoshihiro I. The Role of the $\beta$ Adrenergic Receptor-Mediated Signaling Pathway and p53-Mediated Signaling Pathway in the Apoptosis of Cardiomyocytes. Circ J 2011; 75: 1811 - 1818 .

2. Braunwald E, Bristow MR. Congestive heart failure: fifty years of progress. Circulation. 2000;102:IV14-IV23.

3. Tak WM, Ludger H, Daniela G, Filio B. p53 regulates the cardiac transcriptome. Proceedings of the National Academy of Sciences (PNAS)February 28, 2017114 (9) 2331-2336; first published February 13, 2017 https://doi.org/10.1073/pnas.1621436114

4. Vousden KH, Lu X. Live or let die: The cell's response to p53. Nat Rev Cancer. 2002. 2(8):594-604.

5. Sun Y, Su Q, Li L, Wang X, Lu Y, Liang J. MiR486 regulates cardiomyocyte apoptosis by p53mediated BCL-2 associated mitochondrial apoptotic pathway. BMC Cardiovasc Disord. 2017 May 10;17(1):119. doi: 10.1186/s12872-017-0549-7.

6. Yu-Han Sun, Qiang Su, Lang Li, Xian-Tao Wang, Yuan-Xi Lu, and Jia-Bao Liang. Expression of p53 in myocardium following coronary microembolization in rats and its significance. J Geriatr Cardiol. 2017 May; 14(5): 292-300. doi: 10.11909/.issn.16715411.2017 .05 .007

7. Zhen-Fang Liu, Xiao Zhang, Yan-Xiang Qiao, Wan-Qun Xu, Cheng-Tai Ma, Hua-Li Gu, et al.. Neuroglobin protects cardiomyocytes against apoptosis and cardiac hypertrophy induced by 
isoproterenol in rats. Int $\mathrm{J}$ Clin Exp Med 2015;8(4):5351-5360. www.ijcem.com /ISSN:1940-5901/IJCEM0003652.

8. Mozayani, Ashraf; Raymon, Lionel. Handbook of Drug Interactions: A Clinical and Forensic Guide. Springer Science \& Business Media. 2003. pp. 541-542.

9. Gu J, Noe A, Chandra P, Al-Fayoumi S, Ligueros-Saylan $M$, Sarangapani $R$, et al. Pharmacokinetics and pharmacodynamics of LCZ696, a novel dual-acting angiotensin receptor-neprilysin inhibitor (ARNi). J Clin Pharmacol. 2010 Apr;50(4):401-14. doi: 10.1177/0091270009343932. Epub 2009 Nov 23.

10. Dizaye K, Ali RH. Effects of neprilysin-renin inhibition in comparison with neprilysinangiotensin inhibition on the neurohumoral changes in rats with heart failure. BMC Pharmacology and Toxicology. 2019 Dec;20(1):23.

11. Krenek P, Kmecova J, Kucerova D, Bajuszova Z, Musil P, Gazova A, et al. Isoproterenolinduced heart failure in the rat is associated with nitric oxide-dependent functional alterations of cardiac function. Eur J Heart Fail. 2009;11(2):140-6.

12. Suematsu $Y$, Jing $W$, Nunes $A$, Kashyap $M$, Khazaeli M, Vaziri $N$, et al. LCZ696 (Sacubitril/valsartan), an angiotensin-receptor neprilysin inhibitor, attenuates cardiac hypertrophy, fibrosis, and vasculopathy in a rat model of chronic kidney disease. J Card Fail. 2018;24(4):266-75.

13. Dizaye KF, Ahmed AA. Renoprotective evaluations of different angiotensin inhibitors on diabetic nephropathy in rats. Middle East $\mathrm{J}$ Intern Med. 2016;63(4023):1-9.

14. Bin-Jaliah I, Hussein AM, Sakr HF, Eid EA. Effects of low dose of aliskiren on isoproterenolinduced acute myocardial infarction in rats. Physiol Int. 2018;105(2):127-44.

15. Heraldo GLF, Nestor LF, Rafael Bde Sousa, Eduardo Rde Carvalho, Patrícia LDL, José GLF. Experimental model of myocardial infarction induced by isoproterenol in rats. Brazilian Journal of Cardiovascular Surgery. Print version ISSN 0102-7638. Rev Bras Cir Cardiovasc vol.26 no.3 São José do Rio

Preto July/Sept. 201. http://dx.doi.org/10.5935/1678-9741.20110024

16. Robert K. Multiparametric and semiquantitative scoring systems for the evaluation of mouse model histopathology - a systematic review.
BMC Vet Res. 2013; 9: 123. doi: $\underline{10.1186 / 1746-}$ 6148-9-123

17. Lun-Xiu Q, Zhao-You T, Zeng-Chen M, ZhiQuan W, Xin-Da Z, Qing-Hai Y. p53 immunohistochemical scoring: an independent prognostic marker for patients after hepatocellular carcinoma resection. World $\mathrm{J}$ Gastroenterol. 2002 Jun 15; 8(3): 459-463. doi: 10.3748/wjg.v8.i3.459

18. GraphPad Software, Inc. 7825 Fay Avenue, Suite 230, La Jolla, CA 92037 USA. (Accessed 2018. at https://www.graphpad.com/scientificsoftware/prism/).

19. Heather MW, Lesley C, Paul A.J. B, Keith K. Published online 2018 Dec 31. JACC Basic Transl Sci. v.3(6); 2018 Dec. PMC6314973. doi: 10.1016/j.jacbts.2018.08.006

20.Brian RB , Vasanthi Mowat, Nagai, Abraham Nyska, Yoshimasa Okazaki, Peter J. Clements, et al. Nonproliferative and Proliferative Lesions of the Cardiovascular System of the Rat and Mouse. $\underline{\mathrm{J}}$ Toxicol Pathol. v.29(3 Suppl); 2016

21. Prince A, Amit K, Nilofer S, Preeti K, Chandraiah G. Isoproterenol-induced cardiac ischemia and fibrosis: Plantbasedapproaches for intervention. Phytotherapy Research - July 2018 DOI: 10.1002/ptr.6152.

22. Sally B, Malcolm $Y$, Cheryl S, Thomas W,William G, John T. Cardiac Troponin I in Isoproterenol-Induced Cardiac Injury in the Hanover Wistar Rat: Studies on Low Dose Levels and Routes of Administration. Toxicologic Pathology, 38: 287-291, 2010 ISSN: 0192-6233 print / 1533-1601 online DOI: 10.1177/0192623309357948

23. Jun Z, Alan K, Steven EL, James LW, Eugene $\mathrm{HH}$. Isoproterenol-induced Cardiotoxicity in Sprague-Dawley Rats: Correlation of Reversible and Irreversible Myocardial Injury with Release of Cardiac Troponin $\mathrm{T}$ and Roles of iNOS in Myocardial Injury. Toxicologic Pathology, 36:277-288, $2008 . \quad$ DOI: $10.1177 / 0192623307313010$

24. Masanobu Ishii, Koichi Kaikita, Koji Sato, Daisuke Sueta, Koichiro Fujisue, Yuichiro Arima, et al. Cardioprotective Effects of LCZ696 (Sacubitril/Valsartan) After Experimental Acute Myocardial Infarction. JACC Basic Transl Sci. 2017 Dec; 2(6): 655668. Published online 2017 Dec 25. doi: 10.1016/j.jacbts.2017.08.001

25. Mohd I, Quamrul H, Sayeed A, Obaid R. Sacubitril and valsartan protect from experimental myocardial infarction by ameliorating oxidative damage in Wistar rats. Article in Clinical and Experimental 
Hypertension 41(1):1-8 - March

2018.

DOI: $10.1080 / 10641963.2018 .1441862$

26. Song $\mathrm{H}$, Conte JV Jr, Foster $\mathrm{AH}, \mathrm{McLaughlin}$ JS, Wei C. Increased p53 protein expression in human failing myocardium . J Heart Lung Transplant. 1999 Aug;18(8):7449.

27. Zhou B, Wu LJ, Tashiro S, Onodera S, Uchiumi $F$, Ikejima $T$. Silibinin protects rat cardiac myocyte from isoproterenol-induced DNA damage independent on regulation of cell cycle. Biol Pharm Bull 2006; 29: 1900 - 1905.

28. Sano $M$, Minamino $T$, Toko $H$, Miyauchi $H$, Orimo M, Qin Y, p53-induced inhibition of Hif-1 causes cardiac dysfunction during pressure overload. Nature. 2007;446:444-448.

29. Biswajit $\mathrm{D}$, David Y , Amit V, Sudhiranjan $\mathrm{G}$, Sagartirtha $\mathrm{S}$, Subha Sen. Influence of p53 in the transition of myotrophin-induced cardiac hypertrophy to heart failure. Cardiovasc Res. 2010 Aug 1; 87(3): 524-534. Published online 2010 Mar 3. doi: 10.1093/cvr/cvq068.

30. Birks EJ, Latif N, Enesa K, Folkvang T, Luong IASarathchandraP, et al. Elevated p53 expression is associated with dysregulation of the ubiquitin-proteasome system in dilated cardiomyopathy. Cardiovasc

Res. 2008;79:472-

480. doi:10.1093/cvr/cvn083. [PubMed] [Google Scholar]

31. Su D, Guan L, Gao Q, Li Q, Shi C, Liu Y, et al; ROCK1/p53/NOXA signaling mediates cardiomyocyte apoptosis in response to high glucose in vitro and vivo. Biochim Biophys Acta Mol Basis Dis. 2017 Apr;1863(4):936-946. doi: 10.1016/j.bbadis.2017.01.021. Epub 2017 Jan 26.

32. Stanley-Hasnain S, L. Hauck, D. Grothe, F. Billia. PlumX Metrics. Control of Cardiomyocyte Proliferation Through p53/Mdm2-Regulated MicroRNAs.

DOI: https://doi.org/10.1016/j.healun.2016.01.5 $\underline{10}$

33. Elmore S. Apoptosis: a review of programmed cell death. Toxicologic pathology. 2007 Jun;35(4):495-516.

34. Hassan AF, Kamal MM. Effect of exercise training and anabolic androgenic steroids on hemodynamics, glycogen content, angiogenesis and apoptosis of cardiac muscle in adult male rats. Int J Health Sci (Qassim) 2013; 7: 47-60.

35. Atsuhiko T. Naito, Sho Okada, Tohru Minamino, Koji Iwanaga, Mei-Lan Liu, Tomokazu Sumida. Promotion of CHIPMediated p53 Degradation Protects the Heart from Ischemic Injury. Circulation Research June 11,2010 Ol:10.1161/CIRCRESAHA.109.214346
36. Naito AT, Okada S, Minamino T, Iwanaga K, Liu ML, Sumida T, Nomura S, Sahara N, Mizoroki T, Takashima A, Akazawa $\mathrm{H}$. Promotion of CHIP-mediated p53 degradation protects the heart from ischemic injury. Circulation research. 2010 Jun 11;106(11):1692. 